\title{
Experimental Lung Injury Reduces Krüppel-like Factor 2 to Increase Endothelial Permeability via Regulation of RAPGEF3-Rac1 Signaling
}

\author{
Ru-Ting Huang ${ }^{1 *}$, David Wu ${ }^{1 *}$, Angelo Meliton ${ }^{1}$, Myung-Jin Oh¹, Matthew Krause ${ }^{1}$, Joyce A. Lloyd ${ }^{2}$, \\ Recep Nigdelioglu ${ }^{1}$, Robert B. Hamanaka ${ }^{1}$, Mukesh K. Jain ${ }^{3}$, Anna Birukova ${ }^{1}$, John P. Kress ${ }^{1}$, Konstantin G. Birukov ${ }^{1}$, \\ Gökhan M. Mutlu' ${ }^{1}$, and Yun Fang ${ }^{1}$ \\ ${ }^{1}$ Section of Pulmonary/Critical Care, Department of Medicine, The University of Chicago, Chicago, Illinois; ${ }^{2}$ Department of Human and \\ Molecular Genetics, Virginia Commonwealth University, Richmond, Virginia; and ${ }^{3}$ Case Cardiovascular Research Institute, Case Western
} Reserve University, Cleveland, Ohio

\begin{abstract}
Rationale: Acute respiratory distress syndrome (ARDS) is caused by widespread endothelial barrier disruption and uncontrolled cytokine storm. Genome-wide association studies (GWAS) have linked multiple genes to ARDS. Although mechanosensitive transcription factor Krüppel-like factor 2 (KLF2) is a major regulator of endothelial function, its role in regulating pulmonary vascular integrity in lung injury and ARDS-associated GWAS genes remains poorly understood.
\end{abstract}

Objectives: To examine KLF2 expression in multiple animal models of acute lung injury and further elucidate the KLF2mediated pathways involved in endothelial barrier disruption and cytokine storm in experimental lung injury.

Methods: Animal and in vitro models of acute lung injury were used to characterize KLF2 expression and its downstream effects responding to influenza A virus (A/WSN/33 [H1N1]), tumor necrosis factor- $\alpha$, LPS, mechanical stretch/ventilation, or microvascular flow. KLF2 manipulation, permeability measurements, small GTPase activity, luciferase assays, chromatin immunoprecipitation assays, and network analyses were used to determine the mechanistic roles of
KLF2 in regulating endothelial monolayer integrity, ARDS-associated GWAS genes, and lung pathophysiology.

Measurements and Main Results: KLF2 is significantly reduced in several animal models of acute lung injury. Microvascular endothelial KLF2 is significantly induced by capillary flow but reduced by pathologic cyclic stretch and inflammatory stimuli. KLF2 is a novel activator of small GTPase Ras-related C3 botulinum toxin substrate 1 by transcriptionally controlling Rap guanine nucleotide exchange factor $3 /$ exchange factor directly activated by cyclic adenosine monophosphate, which maintains vascular integrity. KLF2 regulates multiple ARDS GWAS genes related to cytokine storm, oxidation, and coagulation in lung microvascular endothelium. KLF2 overexpression ameliorates LPS-induced lung injury in mice.

Conclusions: Disruption of endothelial KLF2 results in dysregulation of lung microvascular homeostasis and contributes to lung pathology in ARDS.

Keywords: endothelial dysfunction; Rho; GTPase; exchange factor directly activated by cyclic adenosine monophosphate; acute respiratory distress syndrome

(Received in original form April 1, 2016; accepted in final form November 14, 2016)

*These authors contributed equally to this study.

Supported by National Institutes of Health grants HL103789 (Y.F.), ES015024 (G.M.M.), R21 ES025644 (G.M.M.), HL87823 (K.G.B.), HL107920 (A.B.), HL130431 (A.B.), GM114171 (A.B.), T32 HL007381 (M.-J.O.), and T32 HL007605 (D.W.); and the American Heart Association (BGIA7080012, Y.F.).

Author Contributions: Animal models of acute respiratory distress syndrome (ARDS), R.-T.H., D.W., A.M., M.-J.O., R.N., R.B.H., A.B., J.P.K., K.G.B., G.M.M., and Y.F. In vitro models of ARDS, R.-T.H., D.W., J.A.L., M.K.J., A.B., K.G.B., G.M.M., and Y.F. KLF2 regulation of RAPGEF3 and Rac1, R.-T.H., D.W., J.A.L., M.K., M.K.J., and Y.F. Mechanoregulation of KLF2, R.-T.H., D.W., M.K., and M.K.J. KLF2 regulation of ARDS-associated genome-wide association studies genes, R.-T.H., D.W., G.M.M., and Y.F. Manuscript writing, R.-T.H., D.W., G.M.M., and Y.F.

Correspondence and requests for reprints should be addressed to Yun Fang, Ph.D., 5841 South Maryland Avenue, MC 6026, Office M628, Chicago, IL 60637. E-mail: yfang1@medicine.bsd.uchicago.edu

This article has an online supplement, which is accessible from this issue's table of contents at www.atsjournals.org

Am J Respir Crit Care Med Vol 195, Iss 5, pp 639-651, Mar 1, 2017

Copyright $\odot 2017$ by the American Thoracic Society

Originally Published in Press as DOI: 10.1164/rccm.201604-0668OC on November 17, 2016

Internet address: www.atsjournals.org 


\section{At a Glance Commentary}

\section{Scientific Knowledge on the \\ Subject: Disruption of the} endothelial barrier is the sine qua non of acute lung injury and acute respiratory distress syndrome (ARDS). However, how barrier maintenance is regulated under inflammatory states in ARDS requires further investigation.

\section{What This Study Adds to the}

Field: Our research reveals that lung injury reduces Krüppel-like factor 2 (KLF2), the master regulator of endothelial quiescence, and demonstrates that KLF2 activates small GTPase Ras-related C3 botulinum toxin substrate 1 through transcriptional regulation of Rap guanine nucleotide exchange factor $3 /$ exchange factor directly activated by cyclic adenosine monophosphate and stabilizes the vascular barrier, which is a novel mechanism of transcriptional activation of a guanine exchange factor. Moreover, network analyses and experimental results demonstrate that KLF2 plays a central role in regulating many genes associated with ARDS identified by genome-wide association studies.

Lungs are strategically vascularized to achieve efficient gas exchange. The endothelial lining of pulmonary blood vessels maintains a tight barrier between the overlying epithelium exposed to atmospheric gas and the underlying blood flow, and also ensures adequate oxygenation by regulating ventilation/perfusion relationships. Increased endothelial permeability results in parenchymal accumulation of leukocytes, protein, and extravascular water, all hallmarks of acute lung injury (ALI), which is clinically defined as the acute respiratory distress syndrome (ARDS), a devastating condition with high mortality rates $(1,2)$. The normal function of the endothelium can be altered by infectious agents, mechanical factors, and chemicals. The final common pathway is compromised endothelial monolayer integrity (2). Moreover, experimental models of ALI and human genome-wide association studies (GWAS) of ARDS suggest the central pathophysiologic role of cytokine storm (2). Recent studies demonstrate that disruption of endothelial homeostasis contributes significantly to the uncontrolled cytokine storm in ARDS $(3,4)$.

Endothelial barrier function is dynamically regulated by intercellular junctions and cytoskeletal remodeling, which are controlled by the activities of small GTPases, particularly Rho family of GTPases, such as Ras homolog gene family member A (RhoA), Cell Division Cycle 42 (Cdc42), and $\operatorname{Rac1}(5,6)$. Specifically, Ras-related C3 botulinum toxin substrate 1 (Rac1 GTPase), in its activated or GTP-bound state, maintains endothelial monolayer integrity by stabilizing intercellular junctions and by formation of cortical actin $(7,8)$. In contrast, Rac1 inactivation (guanosine diphosphate [GDP]-bound state) is linked to leaky vasculature (9). Racl activity is dynamically modulated by biochemical activators (10) and biomechanical stimuli $(11,12)$. However, it remains unclear whether transcription factors contribute to Rac1-mediated barrier protection.

Transcription factor Krüppel-like factor 2 (KLF2) of the zinc finger family of DNA-binding proteins has recently emerged as a major molecular switch that controls endothelial homeostasis (13-16). KLF2 is evolutionarily conserved between rodents and human and regulates arterial vascular tone by transactivating endothelial nitric oxide synthase (NOS3) and trans-repressing endothelin-1 $(13,14$, 17). KLF2 maintains blood fluidity by increasing thrombomodulin (TM) $(13,14$, 17-19). KLF2 was first cloned from lung tissues and is also known as lung Krüppellike factor (20). Genetic deletion of Klf2 in mice is embryonically lethal because of impaired blood vessel maturation and abnormalities in lung development (21-24). The putative role of KLF2 in inflammatory lung diseases remains poorly understood. We sought to determine if KLF2 plays a role during ALI via small GTPase signaling-mediated cytoskeletal remodeling.

We report that lung Klf2 expression is significantly reduced in vivo in rodent models of ALI induced by influenza virus, LPS, or high-tidal-volume mechanical ventilation, consistent with KLF2 reduction in human pulmonary microvascular cells (HMVEC) subjected to LPS, tumor necrosis factor (TNF)- $\alpha$, or cyclic stretch. Capillary shear stress maintains the physiologic expression of microvascular KLF2 that is suppressed by TNF- $\alpha$. The experiments further establish transcriptional regulation of small GTPases: KLF2 transactivates Rap guanine nucleotide exchange factor 3 (RAPGEF3, also known as EPAC1), which confers Racl activation and enhances endothelial barrier integrity. Moreover, endothelial KLF2 regulates multiple human ARDS candidate genes implicated by GWAS $(25,26)$, particularly those associated with cytokine storm. KLF2 overexpression significantly ameliorates LPS-induced ALI in vivo. These results collectively provide the first evidence linking disruption of KLF2 signaling in the pathogenesis of inflammatory lung diseases and elucidate a new molecular mechanism by which KLF2 regulates microvascular barrier protection via small GTPase signaling.

Some of the results of these studies have been previously reported in the form of an abstract at the 2016 annual meeting of the American Thoracic Society (27).

\section{Methods}

\section{Animals and In Vivo KLF2 Overexpression}

For the mouse models of virus- and bacteria-induced ARDS, C57BL/6J mice were anesthetized and then intratracheally instilled either with influenza $A$ virus (A/WSN/33 [H1N1]) (500 pfu/mouse) or LPS $(0.7 \mathrm{mg} / \mathrm{kg}$ body weight; Escherichia coli O55:B5). Animals were killed after 24 hours. For the rat model of ventilatorinduced lung injury, male Sprague Dawley rats were intubated and LPS $(0.75 \mathrm{mg} / \mathrm{kg})$ was administered via the endotracheal tube. Rats were rotated 90 degrees after each aliquot (supine, right decubitus, prone, and left decubitus) to achieve homogenous LPS distribution. Rats were then extubated for 24 hours and reintubated and ventilated for 8 hours in a volume control mode and randomly assigned to two groups: tidal volume of $12 \mathrm{ml} / \mathrm{kg}$ and respiratory rate of 60 breaths per minute (adjusted to keep end tidal $\mathrm{CO}_{2}$ at $40-45 \mathrm{~mm} \mathrm{Hg}$ ), $\mathrm{FI}_{\mathrm{O}_{2}} 60 \%$, and positive end-expiratory pressure $5 \mathrm{~cm}$ $\mathrm{H}_{2} \mathrm{O}$, or tidal volume $6 \mathrm{ml} / \mathrm{kg}$ and respiratory rate 120 breaths per minute. Bronchoalveolar 
lavage (BAL) and tissue collection were performed. For in vivo human KLF2 transient overexpression, $\mathrm{C} 57 \mathrm{BL} / 6$ mice were tail veininjected with $50 \mu \mathrm{g}$ of KLF2 overexpression plasmid or control plasmid diluted with $5 \%$ glucose and TurboFect in vivo Transfection Reagent (Thermo Scientific, Waltham, MA). After 6 hours, $0.7 \mathrm{mg} / \mathrm{kg}$ LPS or phosphate-buffered saline solution was administered as described above. After an additional 24 hours, BAL and tissue were collected.

Detailed methods of the in vivo and in vitro studies are available in the online supplement.

\section{Results}

\section{Reduced Pulmonary KIf2 in Animal Models of ALI}

In vivo expression of lung Klf2 was determined by three complementary rodent systems that model human ARDS. First, mice were intratracheally administered with influenza A virus (A/WSN/33 [H1N1]) (28) to model viral-pneumonia-induced ARDS. As expected, influenza A virus caused lung inflammation evident by increased expression of $\mathrm{Ccl} 2, \mathrm{Ccl} 4, \mathrm{Il} 6$, and $\mathrm{Cxcl} 2$ (quantitative real-time polymerase chain reaction) (Figure 1A) and elevated cell counts/proteins in BAL fluid (see Figure E1A in the online supplement). Moreover, Klf2 expression was significantly reduced in the lungs with influenza $A$ virus infection (Figure 1A). Second, mice were intratracheally administered with LPS to model bacteriainduced ARDS. Proinflammatory genes and increased cell counts/protein in BAL (see Figure E1B) were induced in LPS-treated lung, accompanied by significant reduction in Klf2 (Figure 1B). A third animal model was developed to investigate the effect of high tidal volume ventilatory support, which is associated with ventilatorinduced lung injury in patients with ARDS (29). Rats were first subjected to intratracheal administration of LPS for 24 hours, followed by intubation and mechanical ventilation at high $(12 \mathrm{ml} / \mathrm{kg})$ or low tidal volumes $(6 \mathrm{ml} / \mathrm{kg})$ for 8 hours. Figure $1 \mathrm{C}$ shows increased inflammation and reduced $K l f 2$, accompanied by lung injury (see Figure E1C) in the rat lungs subjected to high tidal volume ventilation. All animal models demonstrate significant reduction in $K l f 2$ expression associated with lungs subjected to ALI.
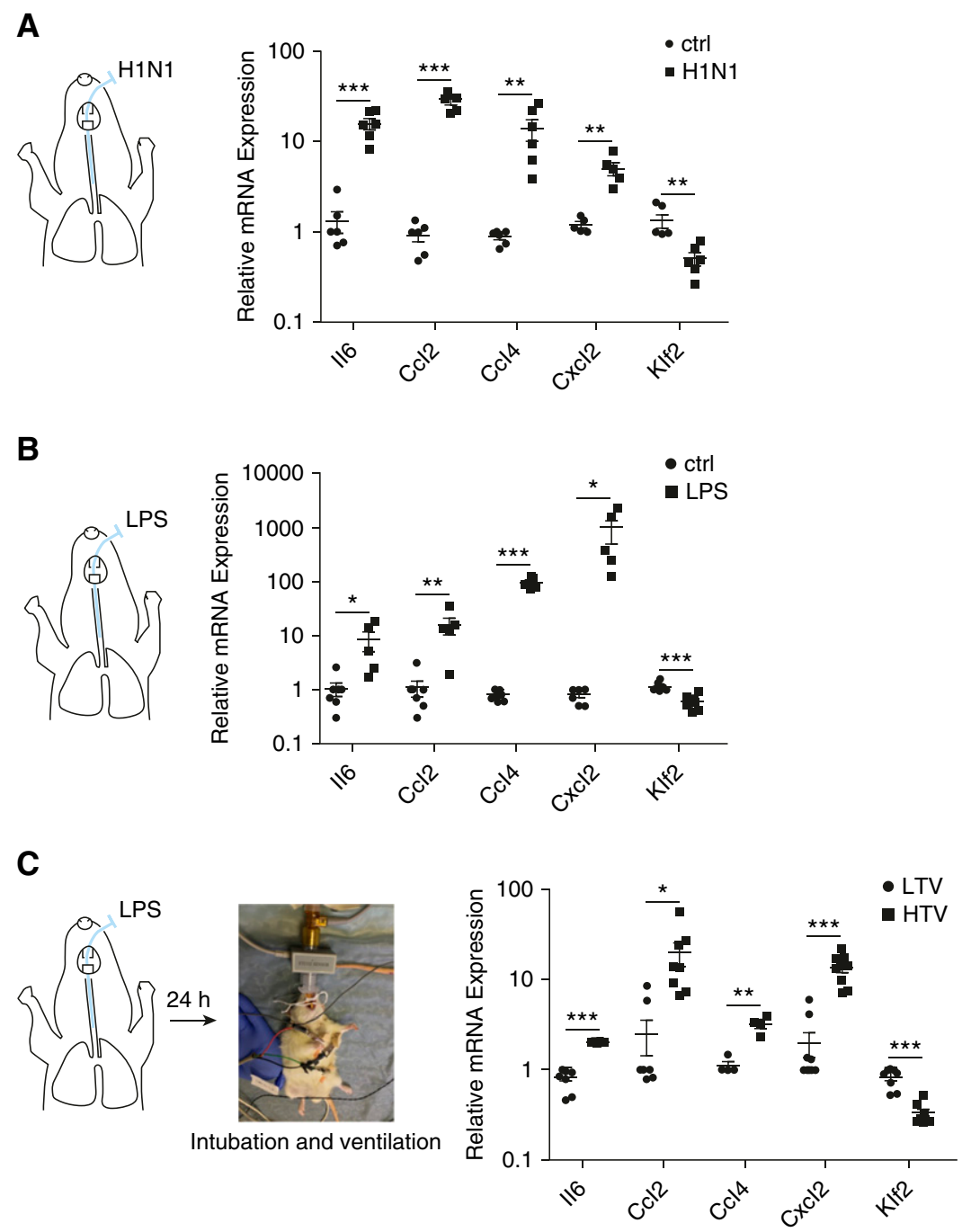

Figure 1. Pulmonary Krüppel-like factor 2 (Klf2) is down-regulated by inflammation induced by influenza AWSN/H1N1 virus (H1N1) infection, LPS administration, or LPS administration followed by high tidal volume ventilation in vivo. (A) Mice were infected with 500 multiplicity of infection of influenza AWSN/H1N1 for 2 days and killed to collect lung tissues for RNA isolation followed by quantitative real-time polymerase chain reaction (qRT-PCR). mRNA expression for $1 / 6, \mathrm{Ccl} 2, \mathrm{Cc} / 4$, and $\mathrm{Cxcl} 2$ in $\mathrm{H} 1 \mathrm{~N} 1$-infected mice are significantly elevated, whereas Klf2 expression is decreased compared with control (ctrl) mice. $n=6$. (B) Mice were intratracheally administrated with $0.7 \mathrm{mg} / \mathrm{kg}$ LPS for 24 hours and killed to collect lung tissues for RNA isolation followed by qRT-PCR. mRNA expression for II6, Ccl2, $\mathrm{CCl} 4$, and $\mathrm{CxCl} 2$ are significantly elevated in LPS-challenged mice, whereas KIf2 expression is decreased compared with control (ctrl) mice. $n=5-9$. (C) Rats were ventilated with a tidal volume of $12 \mathrm{ml} / \mathrm{kg}$ (high tidal volume) or $6 \mathrm{ml} / \mathrm{kg}$ (low tidal volume) for 8 hours after 24-hour LPS administration and then killed to collect lung tissues for RNA isolation followed by qRT-PCR. mRNA expression for $1 / 6$, $\mathrm{Ccl} 2, \mathrm{Cc} / 4$, and $\mathrm{Cxc} / 2$ in high tidal volume rats are significantly elevated, whereas Klf2 expression is decreased compared with low tidal volume rats. $n=4-9$. All data are represented as fold change. Error bars represent \pm SEM. ${ }^{*} P<0.05,{ }^{\star \star} P<0.01,{ }^{\star \star \star} P<0.001$, Student's $t$ test. $C$ Cl $2=C$-C motif chemokine ligand 2; $\mathrm{C} / 4=\mathrm{C}-\mathrm{C}$ motif chemokine ligand 4; $\mathrm{CxCl} 2=\mathrm{C}-\mathrm{X}-\mathrm{C}$ chemokine ligand 2; $\mathrm{HTV}=$ high tidal volume; LTV = low tidal volume.

\section{Pathologic Cyclic Stretch and Inflammatory Stimuli Inhibit KLF2 in HMVEC}

We then tested the hypothesis that endothelial KLF2 expression is dynamically regulated by vascular overdistention, such as that seen in high tidal volume ventilation. Cyclic stretch at $18 \%$ (nonphysiologic) was previously reported to cause vascular damage, such as enhanced endothelial permeability $(30,31)$. KLF2 expression was measured in HMVEC subjected to $5 \%$ 
A

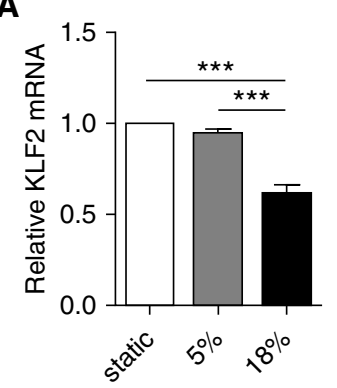

B

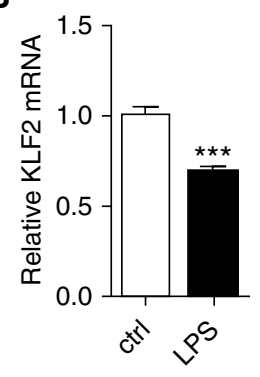

C

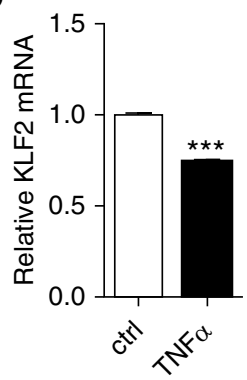

D

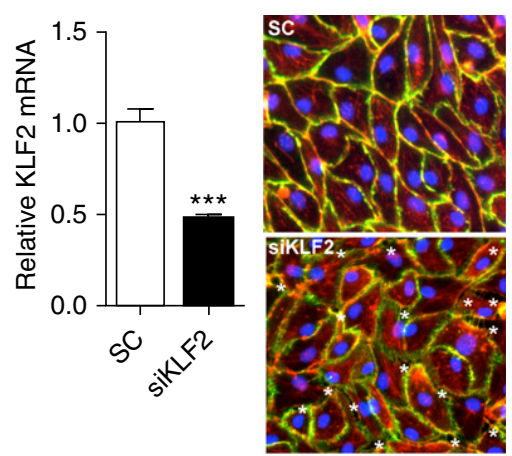

$\mathbf{F}$
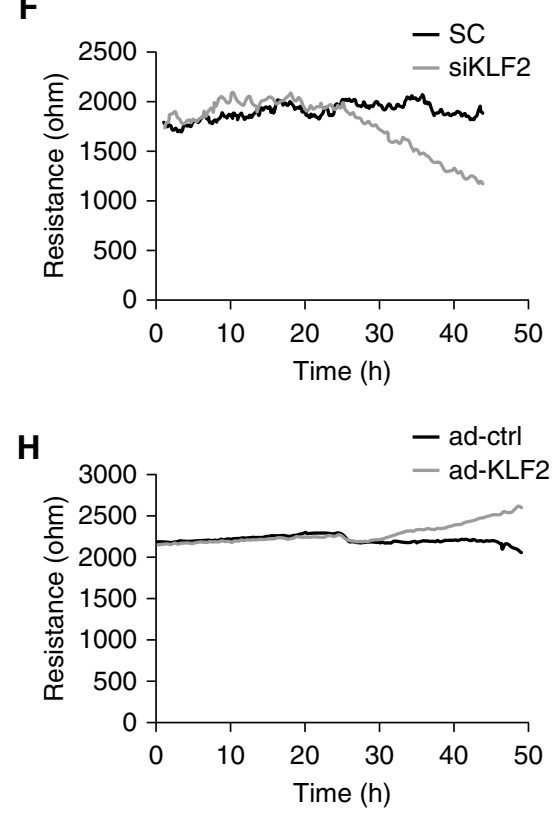

E

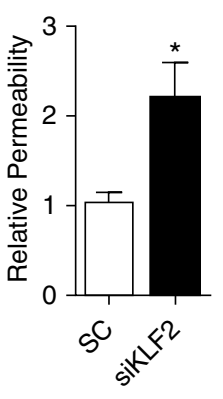

G
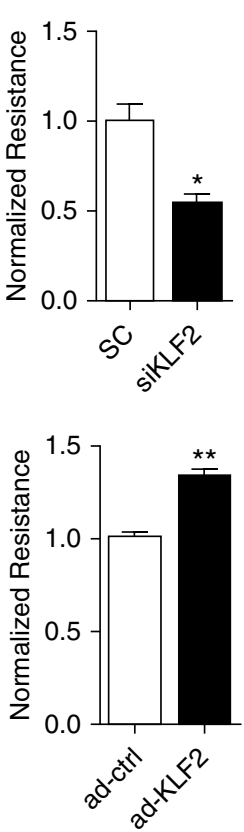

Figure 2. Krüppel-like factor 2 (KLF2) expression is down-regulated by $18 \%$ pathologic stretch and inflammatory stimuli, and regulates intracellular gap formation and monolayer integrity of human pulmonary microvascular cells (HMVEC). (A) HMVEC were subjected to static (no stretch), $5 \%$, or $18 \%$ stretch for 24 hours and harvested for RNA isolation followed by quantitative real-time polymerase chain reaction (qRT-PCR). $\mathrm{n}=10$. (B) HMVEC were treated with $200 \mathrm{ng} / \mathrm{ml}$ LPS for 24 hours and harvested for RNA isolation followed by qRT-PCR. KLF2 mRNA expression is significantly decreased compared with control cells (ctrl) treated with phosphate-buffered saline. $n=4-5$. (C) HMVEC were treated with $10 \mathrm{ng} / \mathrm{ml}$ tumor necrosis factor- $\alpha$ (TNF $\alpha$ ) for 24 hours and harvested for RNA isolation followed by qRT-PCR. KLF2 mRNA expression is significantly decreased compared with control cells treated with phosphate-buffered saline. $n=4-6$. (D) HMVEC transfected with control siRNA (SC) or siRNA targeting KLF2 (siKLF2) for 48 hours were harvested for KLF2 mRNA expression (left panel, $\mathrm{n}=10$ ), or immunostained for VE-Cadherin (green), phalloidin (red), and 4',6-diamidino-2phenylindole (b/ue) to indicate intracellular gaps (asterisks; middle panel), which were quantified by the

(physiologic) or $18 \%$ cyclic stretch for 24 hours. We detected a significant KLF2 reduction in HMVEC exposed to $18 \%$ circumferential stretch when compared with cells under static condition; 5\% stretch has no effect on KLF2 expression (Figure 2A). An 18\% stretch-induced KLF2 suppression was not detected in endothelium isolated from other vascular beds (see Figure E2).

To determine whether microvascular endothelial KLF2 is regulated by inflammatory stimuli associated with lung infections, KLF2 was measured in HMVEC treated with LPS and TNF- $\alpha$. Treatment with LPS or TNF- $\alpha$ for 24 hours led to a significant reduction of KLF2 in HMVEC (Figures $2 \mathrm{~B}$ and $2 \mathrm{C}$ ), accompanied by increased expression of CCL2, IL-6, IL-8, and SELE (see Figure E3).

\section{KLF2 Preserves Pulmonary Microvascular Barrier Function}

Increased pulmonary vascular permeability is a hallmark of ARDS pathogenesis. To establish the putative role of KLF2 in governing pulmonary microvascular integrity, endothelial permeability was determined in HMVEC in which endogenous KLF2 expression was modulated. Monolayer integrity was measured by three independent methods in HMVEC, in which KLF2 is reduced by either gene-targeted small interfering RNAs (siRNAs) or overexpressed by adenoviruses. As shown in Figure 2D, KLF2-targeted siRNAs (siKLF2) reduced endogenous KLF2 mRNA by approximately $53 \%$, and notably increased the intercellular gap formation $(3.33 \%$ vs. $0.01 \%$ gap area in control subjects). Compromised monolayer integrity in KLF2-deficient HMVEC was further demonstrated by the elevated trans-monolayer permeability determined by an XPerT Assay (see Figure E4) (32) that quantifies the mass transport of macromolecular tracers (A488-streptavidin) across a cell monolayer. Figure 2E demonstrates that macromolecule transport was significantly higher in HMVEC treated with siKLF2. The role of KLF2 in maintaining microvascular integrity is also supported by the real-time measurement of transendothelial electrical resistance (TER). Knockdown of endogenous KLF2 significantly reduced TER in HMVEC monolayer by approximately $47 \%$ (Figure $2 \mathrm{~F}$ ) at 2 days. In contrast, overexpression of KLF2 using adenoviral 
A

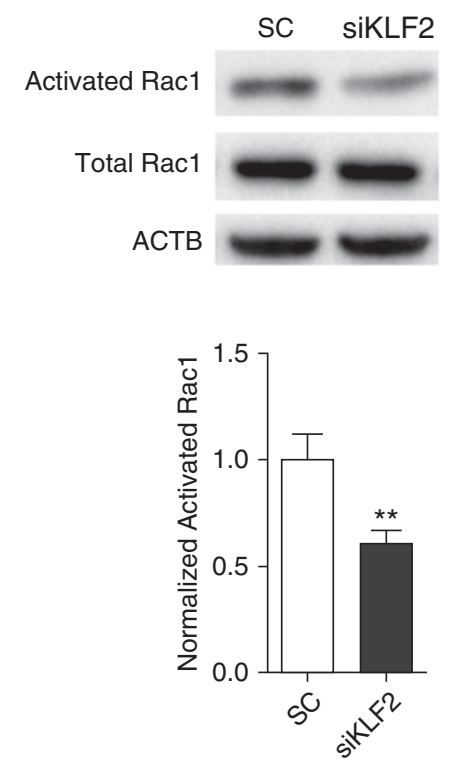

B
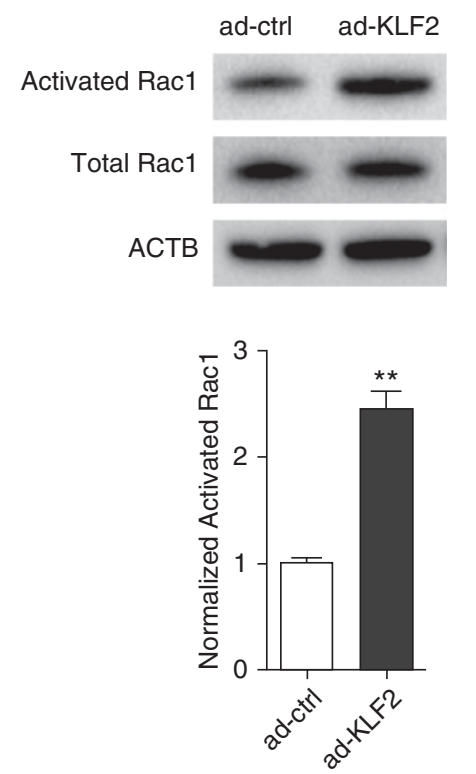

C

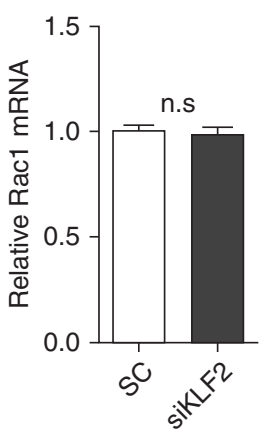

D

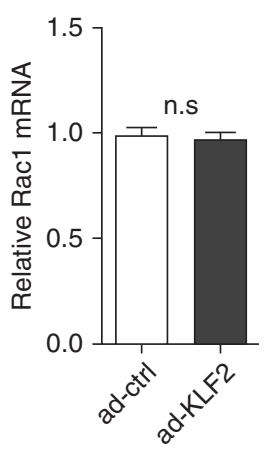

Figure 3. Krüppel-like factor 2 (KLF2) mediates Rac1 activation in human pulmonary microvascular cells. (A) Knockdown of endogenous KLF2 reduces Rac1 activation. Activated Rac1 was evaluated using Rac1 pull-down assay and normalized to the total Rac1 content in cell lysates. The mean fold change of normalized activated Rac1 is lower in siRNA targeting KLF2 (siKLF2)-treated human pulmonary microvascular cells. $n=6$. (B) Overexpression of KLF2 via adenoviral transduction (ad-KLF2) promotes Rac1 activation when compared with control cells (ad-ctrl). Normalized activated Rac1 was determined as previously described in $A$. (C) siKLF2 does not impact relative Rac1 mRNA expression. (D) ad-KLF2 does not impact relative Rac1 mRNA expression. $\mathrm{n}=4$. All data are represented as mean \pm SEM. ${ }^{\star \star} P<0.01$, Student's $t$ test. ACTB = actin- $\beta$; $n$.s. = not significant; Rac1 = Ras-related C3 botulinum toxin substrate 1 ; $\mathrm{SC}=$ control siRNA; siRNA = small interfering RNA.

transduction increased KLF2 mRNA expression (Figure $2 \mathrm{G}$ ) and resulted in a significant increase in TER (Figure $2 \mathrm{H}$ ), suggesting strengthening of endothelial barrier function by KLF2 induction.

\section{KLF2 Activates Rac1 in HMVEC}

Activation of small GTPase Rac1 is associated with stabilized cortical actin and increased vascular barrier function $(7,33)$. We hypothesized that endothelial KLF2 mediates vascular monolayer integrity by modulating Rac1 activity. Racl activation is determined by the activated GTP-bound state and inactive GDP-bound state (5). As shown in Figure 3A, a GTPase pull-down assay detects an approximately $40 \%$ reduction of activated GTP-bound Racl as the result of KLF2 knockdown. Conversely, KLF2 overexpression significantly increases the GTP-bound Racl (2.5-fold) in HMVEC (Figure 3B). Notably, Rac1 mRNA levels are not affected by KLF2 knockdown or overexpression (Figures 3C and 3D). These data demonstrate that KLF2 is a novel indirect activator of small GTPase Rac1, given the insensitivity of Rac1 mRNA to KLF2 manipulation.

\section{KLF2 Transcriptionally Activates Rap Guanine Nucleotide Exchange Factor 3}

Because KLF2 increases Rac1 activity but not Rac1 expression, we tested the hypothesis that KLF2 transcriptionally controls upstream regulators that activate
Rac1. T-lymphoma invasion and metastasisinducing protein-1 (TIAM1) and vav Guanine Nucleotide Exchange Factor 2 (VAV2) are two critical guanine nucleotide exchange factors that facilitate the release of GDP and binding of GTP to Rac1 $(10,34)$. Our results show that TIAM1 and VAV2 expression are not modulated in HMVEC monolayer with KLF2 knockdown or overexpression (see Figures E5 and E6). We then asked whether KLF2 regulates RAPGEF3 expression, because RAPGEF3 was recently identified as a major activator of Rac1 in vascular endothelium (35-38). Figures $4 \mathrm{~A}$ and $4 \mathrm{~B}$ show that KLF2 inhibition in HMVEC significantly reduced RAPGEF3 both at the mRNA and protein level and, conversely, adenovirus-mediated

Figure 2. (Continued). percentage of area covered by gaps. siKLF2-treated HMVEC have a significantly higher percentage of gap area compared with control (right panel, $\mathrm{n}=10$ ). $(E)$ In the fluorescence-based Xpert assay (see Figure E4), HMVEC treated with siKLF2 demonstrate increased permeability. $n=8$. ( $F$ ) KLF2 knockdown disrupts HMVEC barrier integrity, as shown by real-time transendothelial resistance measurements conducted by Electric Cell-substrate Impedance Sensing assay (left). Quantification was conducted 48 hours after siRNA transfection (right). $\mathrm{n}=4$. (G) Overexpression of KLF2 via adenoviral transduction (ad-KLF2) shows more than 32-fold KLF2 mRNA overexpression when compared with control (ad-ctrl). $\mathrm{n}=9$. ( $H$ ) Overexpression of KLF2 via adenoviral transduction enhances HMVEC monolayer integrity (left). Quantification was conducted 48 hours after adenoviral transduction and shown by normalized transendothelial resistance $($ right). $n=5$. All data are represented as mean \pm SEM. ${ }^{\star} P<0.05,{ }^{\star \star} P<0.01,{ }^{\star \star \star} P<0.001$, Student's $t$ test. siRNA $=$ small interfering RNA. 
A
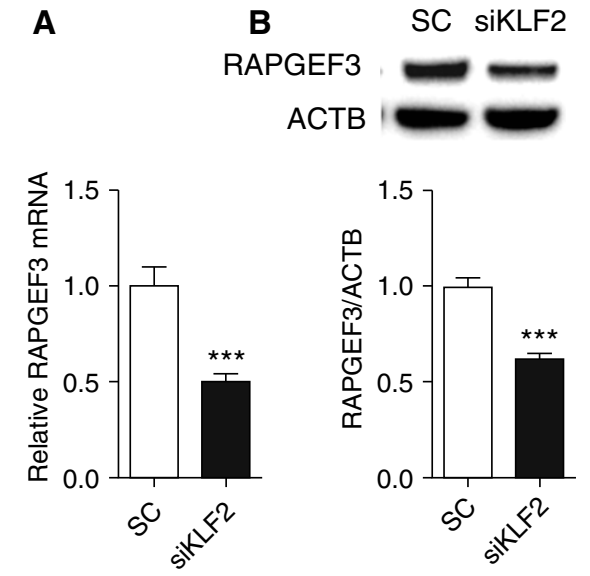

$\mathbf{F}$

WT - CACCC - CACCC CACCC CACCC CACCC mut - GTACT GTACT GTACT GTACT GTACT-
C

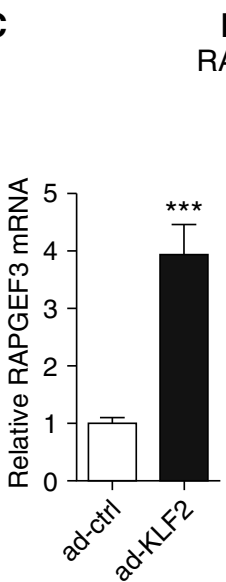

G

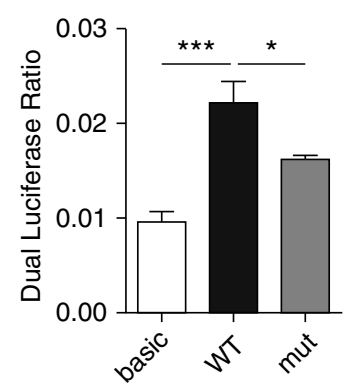

D ad-ctrl ad-KLF2

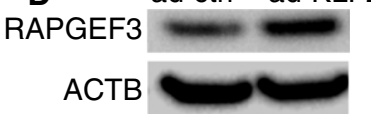

E
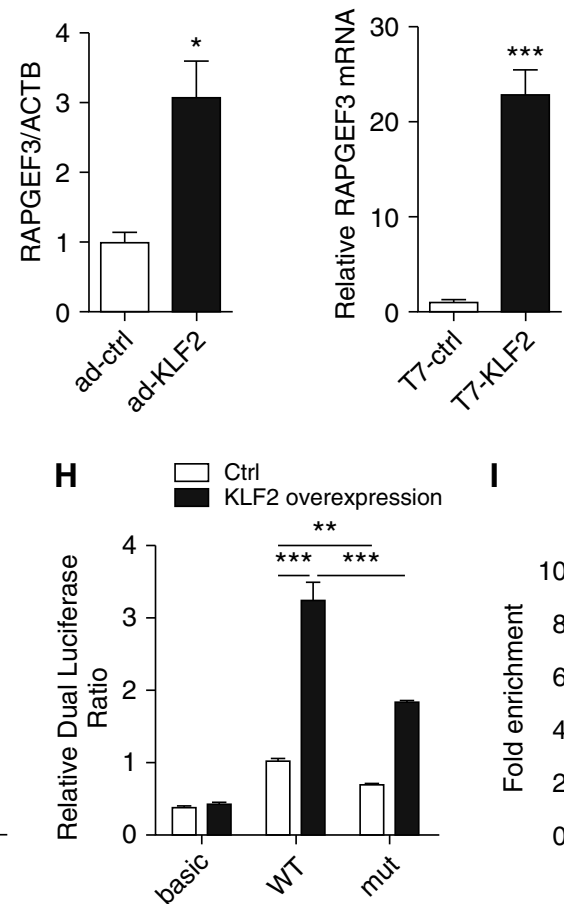

I

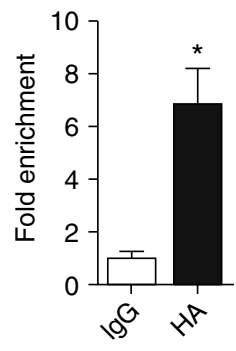

Figure 4. Krüppel-like factor 2 (KLF2) regulates pulmonary microvascular Rap guanine nucleotide exchange factor 3 (RAPGEF3) expression through RAPGEF3 promoter activity. In human pulmonary microvascular cells (HMVEC) deficient for KLF2 (siKLF2), (A) RAPGEF3 mRNA and (B) RAPGEF3 protein expression are significantly reduced. In HMVEC overexpressing KLF2 via adenoviral transduction (ad-KLF2) (C) RAPGEF3 mRNA, and (D) RAPGEF3 protein expression are elevated compared with control cells (ad-ctrl). $n=5-10$. (E) In HMVEC overexpressing KLF2 via transfection with KLF2 transcripts (T7-KLF2), RAPGEF3 mRNA expression is significantly increased compared with cells transfected with AUG-mutated control transcripts (T7-ctrl). $\mathrm{n}=7$. $(F)$ Schematic representation of RAPGEF3 promoter containing multiple CACCC motifs $(W T)$ and mutated RAPGEF3 promoter with five CACCC motifs replaced by GTACT (mut). (G) Intrinsic promoter activity of RAPGEF3 promoter reporter. HEK cells were cotransfected with RAPGEF3 promoter constructs (WT or mut) or the promoter-less vector (basic) and pRL-TK. Promoter activities were indicated by the dual luciferase ratio. $(H)$ KLF2 overexpression via plasmid transfection promotes RAPGEF3 promoter activity, and enhancement of KLF2 on RAPGEF3 promoter activity was diminished in mutated RAPGEF3 promoter. $n=4-13$. () ChIP-quantitative polymerase chain reaction analysis from HMVEC transfected with KLF2 transcripts with HA tag. ChIP was performed with either a control IgG antibody or the antibody against HA followed by quantitative polymerase chain reaction using primers for RAPGEF3 promoter. $\mathrm{n}=5$. All data are represented as mean \pm SEM. ${ }^{\star} P<0.05,{ }^{\star \star} P<0.01,{ }^{\star \star \star} P<0.001$, Student's $t$ test. ACTB $=$ actin- $\beta$; ChIP = chromatin immunoprecipitation; $\mathrm{HA}=$ hemagglutinin; HEK = human embryonic kidney; $\mathrm{pRL}-\mathrm{TK}=$ Renilla luciferase control reporter vectors; $\mathrm{SC}=$ control siRNA; siRNA = small interfering RNA; WT = wild type.

KLF2 overexpression enhanced RAPGEF3 mRNA transcription by approximately fourfold (Figure 4C) and increased protein expression by approximately threefold (Figure 4D). The up-regulation of endothelial RAPGEF3 by KLF2 was further validated by a complementary approach to induce KLF2 expression in HMVEC. In vitro transcription was used to prepare wild-type human KLF2 transcripts and mutant KLF2 transcripts in which the translation start codons (AUGs) were mutated to disrupt translation. RAPGEF3 was significantly increased in HMVEC transfected with wild-type KLF2 transcripts when compared with cells treated with AUGsmutated KLF2 transcripts (Figure 4E).
RAPGEF3 transactivation by KLF2 is further supported by the presence of multiple KLF2 binding sites in the human RAPGEF3 promoter. Encyclopedia of DNA Elements studies indicate an 896-bp region upstream of human RAPGEF3 as a putative promoter in which we identified five CACCC elements that are well-established KLF2 binding sequences (16). Dualluciferase reporter assay was used to determine the activity of this putative human RAPGEF3 promoter and more importantly, to examine its response to KLF2. The assays were conducted using both wild-type RAPGEF3 promoter and a mutated sequence in which CACCC sites were replaced by GTACT to disrupt KLF2 binding (Figure 4F). Figure 4G demonstrates that human RAPGEF3 putative promoter increased the luciferase activity by approximately twofold when compared with the promoter-less control subjects; CACCC $\rightarrow$ GTACT mutation significantly abolished the RAPGEF3 promoter activity. KLF2 overexpression significantly increased luciferase expression on the wild-type promoter, and again, mutated putative KLF2 binding sites significantly diminished luciferase expression (Figure 4H). Moreover, the physical binding between KLF2 and RAPGEF3 promoter was confirmed by 
chromatin immunoprecipitation polymerase chain reaction (Figure 4I).

\section{KLF2 Promotes Rac1 Activation and Barrier Function by Transactivating Endothelial RAPGEF3}

Additional experiments were conducted to delineate whether KLF2-mediated barrier protection is dependent on the RAPGEF3Rac1 signaling. First, using RAPGEF3 knockdown, we detected a significant reduction of Racl activation (GTP-bound Rac1) (Figure 5A), accompanied with increased monolayer permeability (Figure 5B), establishing a significant role for RAPGEF3 in activating Rac1 and promoting monolayer integrity in HMVEC.
KLF2 overexpression significantly increased the RAPGEF3 mRNA (Figure 5C),

RAPGEF3 protein (Figure 5A), GTP-bound Rac1 (Figure 5A), and HMVEC monolayer barrier function (Figure 5B); notably, increased Rac1 activation and barrier function were reduced in KLF2overexpressing cells by RAPGEF3 inhibition. Moreover, RAPGEF3 overexpression significantly promoted barrier function in HMVEC and partially restored the monolayer integrity in KLF2deficient cells (Figure 5D). These data collectively demonstrate that RAPGEF3 contributes to increased Racl activation and enhanced monolayer integrity in HMVEC.
Pulmonary Microvessel Shear Stress Up-regulates KLF2, RAPGEF3, NOS3, and TM in HMVEC, Which Are Inhibited by Inflammatory Stimuli In HMVEC, both NOS3 and TM were significantly reduced with KLF2 knockdown (Figure 6A). Conversely, KLF2 overexpression led to increased expression of NOS3 and TM (Figure 6B), demonstrating KLF2 positively regulates NOS3 and TM in lung microvascular endothelium.

In addition to cyclic stretch as the result of respiration, lung microvascular endothelia are subjected to tangential frictional
A

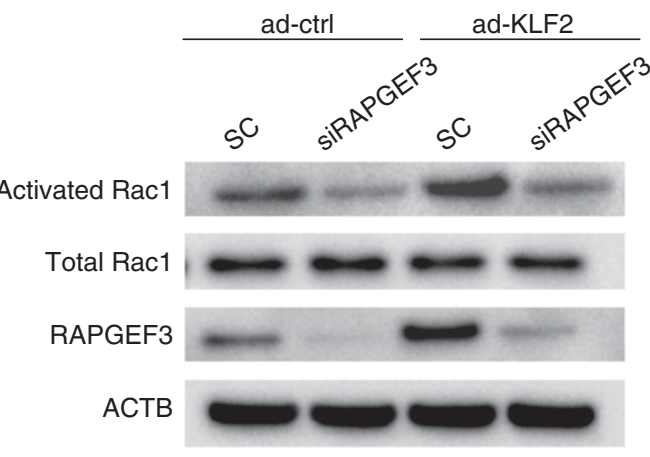

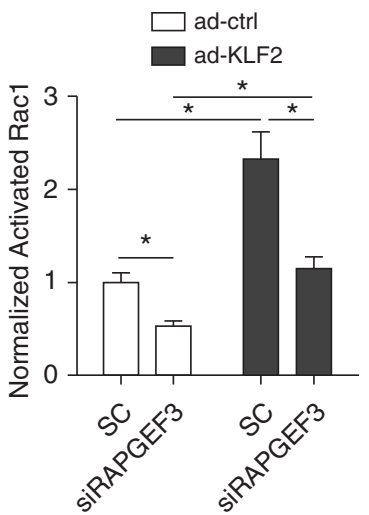

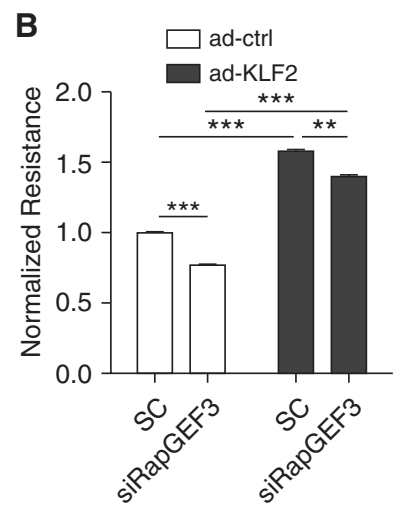

C

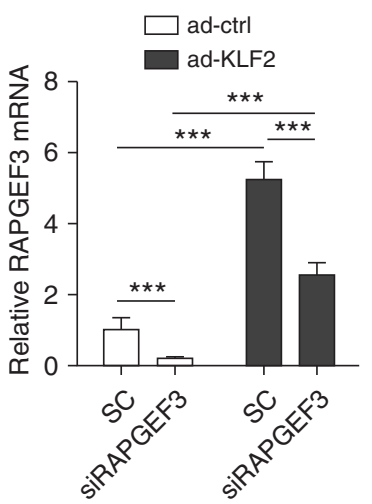

D $\quad-\mathrm{SC}+\mathrm{ctrl}$

- siKLF2+ctrl

..... SC+RAPGEF3 overexpression

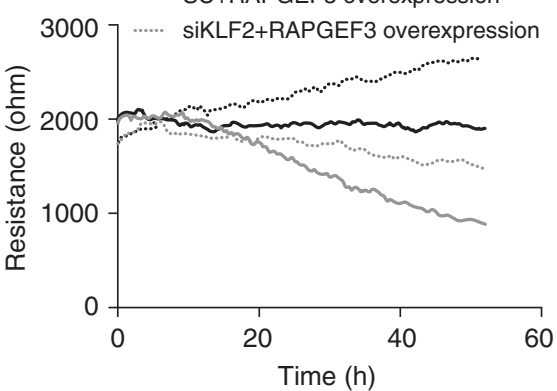

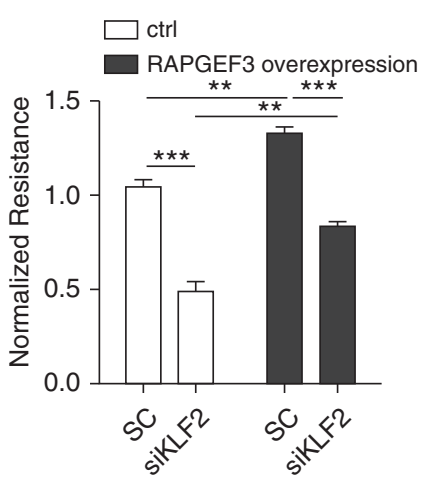

Figure 5. Krüppel-like factor 2 (KLF2) promotes Rac1 activation and barrier function by transactivating endothelial Rap guanine nucleotide exchange factor 3 (RAPGEF3). (A) KLF2 overexpression restores Rac1 activation reduced by RAPGEF3 depletion. Human pulmonary microvascular cells (HMVEC) were transfected with $50 \mathrm{nM}$ siRNA targeting RAPGEF3 (siRAPGEF3) or control siRNA (SC) for 24 hours followed by KLF2 overexpression via adenoviral transduction (ad-KLF2). Activated Rac1 pull-down assay was performed as previously described. The mean fold change of normalized activated Rac1 is shown on the right. $\mathrm{n}=3$. (B) KLF2 overexpression promotes monolayer integrity in HMVEC deficient for RAPGEF3, as shown by normalized TER. Quantification was conducted 48 hours after adenoviral transduction. $\mathrm{n}=4$. (C) KLF2 overexpression significantly increased RAPGEF3 mRNA expression in HMVEC transfected with siRAPGEF3 or SC. $\mathrm{n}=8-11$. (D) RAPGEF3 overexpression partially restores monolayer integrity in HMVEC deficient for KLF2 (left), as shown by normalized TER (right). HMVEC were transfected with $50 \mathrm{nM}$ siKLF2 or SC, followed by RAPGEF3 overexpression via transfection with RAPGEF3 transcripts. Quantification was conducted 48 hours after RAPGEF3 overexpression. $\mathrm{n}=4$. All data are represented as mean $\pm \mathrm{SEM} .{ }^{\star} P<0.05,{ }^{\star \star} P<0.01,{ }^{\star \star \star} P<0.001$, Student's $t$ test. ACTB = actin- $\beta$; ad-ctrl = adenovirus control; ctrl = control; Rac1 = Ras-related C3 botulinum toxin substrate 1; siKLF2 = siRNA against $\mathrm{KLF} 2$; siRNA = small interfering RNA; TER = transendothelial resistance. 
force generated by blood flow.

The narrow inner radius of pulmonary microvessels leads to considerable physiologic shear stress that is comparable with systemic circulation $\left(\sim 5.6 \mathrm{dyn} / \mathrm{cm}^{2}\right)$ (39). Steady flow of $10 \mathrm{dyn} / \mathrm{cm}^{2}(6 \mathrm{~h})$ significantly induced KLF2 expression in HMVEC by approximately threefold when compared with cells under static conditions (Figure 6C). In addition, KLF2 direct downstream targets RAPGEF3, NOS3, and TM were induced by microvessel shear stress in HMVEC. It was reported that during ALI, TNF- $\alpha$ promotes shedding of glycocalyx (40), a putative flow sensor (41). To investigate this, we examined the flowregulation of KLF2, RAPGEF3, NOS3, and TM in HMVEC stimulated by TNF- $\alpha$. As shown in Figure 6C, TNF- $\alpha$ pretreatment (30 min; $50 \mathrm{ng} / \mathrm{ml}$ ) had no effect on KLF2, RAPGEF3, NOS3, and TM expression in HMVEC under static conditions, but significantly reduced the flow-mediated induction of KLF2 (control, $3.29 \pm 0.13$-fold; TNF- $\alpha, 1.35 \pm 0.14$-fold), RAPGEF3 (control, $3.49 \pm 0.22$-fold; TNF- $\alpha, 1.83 \pm$ 0.15 -fold), NOS3 (control, $2.67 \pm 0.19$-fold; TNF- $\alpha, 1.08 \pm 0.11$-fold), and TM (control, $2.79 \pm 0.19$-fold; TNF- $\alpha, 1.11 \pm 0.10$-fold).

The in vivo expression of Rapgef 3, Nos3, and $T m$ were determined in rodent lungs of ALI. All three Klf2 direct targets were significantly reduced in ARDS lungs induced by influenza A viruses (Figure 6D), high tidal volume ventilation (Figure $6 \mathrm{E}$ ), and LPS (Figure 7A).

\section{In Vivo KIf2 Overexpression Ameliorates LPS-induced ALI}

We next used cationic polymers that effectively deliver KLF2-overexpressing constructs to mouse lungs. KLF2 induction in vivo increased the pulmonary expression of Rapgef3, Nos3, Tm, and reduced inflammatory biomarkers ( $\mathrm{Ccl} 2, \mathrm{Ccl} 4$, and $\mathrm{Cxcl2}$ ) in control mice (Figure 7A) and attenuated the reduction of Rapgef 3 , Nos3, and Tm and lessened the expression of inflammatory biomarkers in LPS-treated mouse lungs (Figure 7A). Protein measurements and cell counts in the BAL fluid demonstrate that LPS-induced lung injury was significantly lessened by KLF2 overexpression (Figures $7 \mathrm{~B}$ and $7 \mathrm{C}$ ).

\section{KLF2 Regulates Genes Associated with Human ARDS In Vitro and In Vivo}

Recent efforts in GWAS have identified approximately 25 candidate genes that contribute to the pathogenesis of and/or susceptibility to ARDS in humans $(25,26)$. Ingenuity Pathway
A

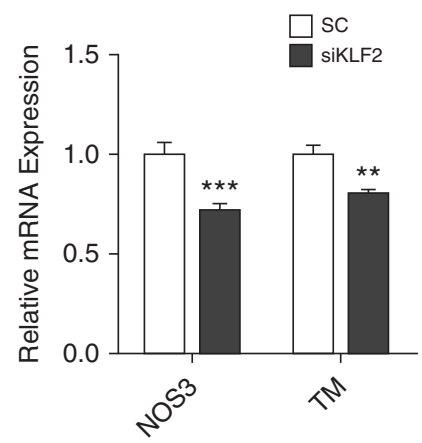

D

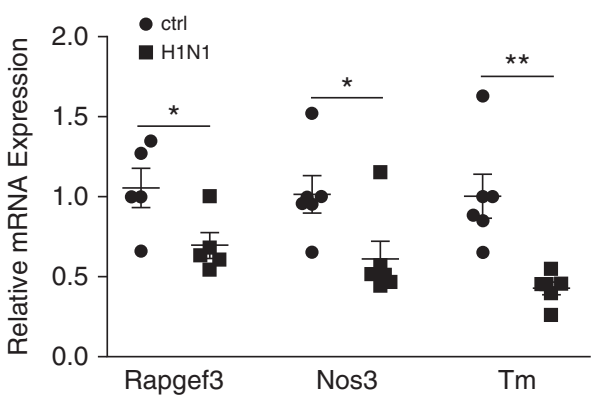

B

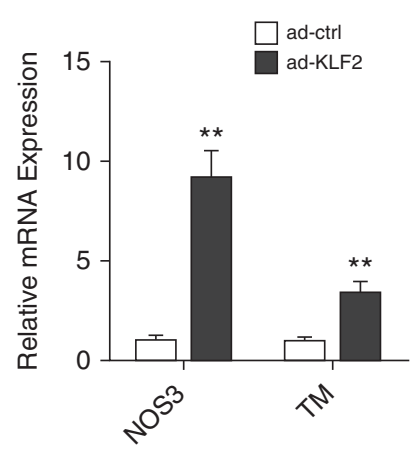

E

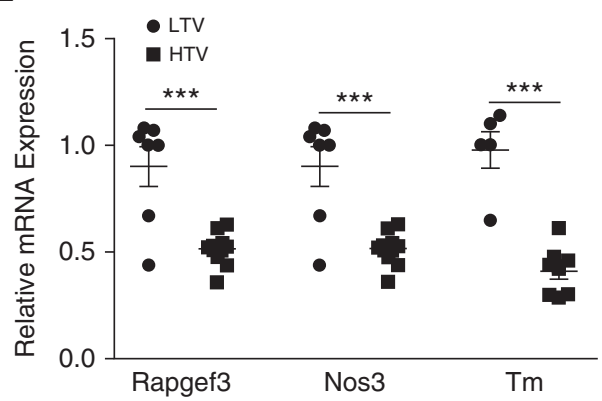

Figure 6. Flow-sensitive Krüppel-like factor 2 (KLF2) regulates Rap guanine nucleotide exchange factor 3 (RAPGEF3), nitric oxide synthase (NOS3), and thrombomodulin (TM) in vitro and in vivo. (A) In KLF2-depleted human pulmonary microvascular cells (HMVEC) (siKLF2), NOS3 and TM mRNA expression are decreased compared with scrambled control (SC), whereas (B) in HMVEC with KLF2 overexpression (ad-KLF2) by adenoviral transduction, NOS3 and TM mRNA expression are up-regulated compared with control virus (ad-ctrl) transduced cells. $\mathrm{n}=7-9$. (C) HMVEC were pretreated with tumor necrosis factor (TNF)- $\alpha(50 \mathrm{ng} / \mathrm{ml}$ ) or phosphate-buffered saline (PBS) (ctrl) for $30 \mathrm{minutes}$ and then subjected to steady flow (flow) of $10 \mathrm{dyn} / \mathrm{cm}^{2}$ or no flow (static) for 6 hours. Relative mRNA expression of KLF2, RAPGEF3, NOS3, and TM are all up-regulated by flow in PBS-treated cells. TNF- $\alpha$ pretreatment significantly abolishes the flow-regulation of KLF2, RAPGEF3, NOS3, and TM in HMVEC. Rapgef3, Nos3, and Tm mRNA expression are decreased in mice infected with H1N1 $(D)$ and in rats with LPS administration followed by high tidal volume ventilation $(E) . n=5-9 .(A-C)$ All data are represented as mean \pm SEM. ( $D$ and $E)$ All data are represented as fold change. Error bars represent \pm SEM. ${ }^{\star} P<0.05,{ }^{\star \star} P<0.01$, ${ }^{* \star *} P<0.001$, Student's $t$ test. $\mathrm{H} 1 \mathrm{~N} 1=$ influenza A virus $(\mathrm{A} / \mathrm{WSN} / 33)$; HTV $=$ high tidal volume; $\mathrm{LTV}=$ low tidal volume; siKLF2 = small interfering RNA against KLF2. 
Analysis (IPA) is a system that transforms a list of genes of interest into a set of relevant networks based on reported biologic interactions (42). Our IPA inquiry (Figure 8A) demonstrates that ARDS-associated GWAS genes and
KLF2 form a highly interconnected network, indicating KLF2 regulation of IL6, IL8, angiotensin I-converting enzyme (ACE), NAD(P)H dehydrogenase, quinone 1 (NQO1), plasminogen activator inhibitor
(SERPINE1/PAI-1), TNF, and nuclear factor- $\kappa \mathrm{B}(\mathrm{NF}-\kappa \mathrm{B})$ inhibitor $\alpha$ (NFKBIA). Because IPA uses known biologic information not limited to microvascular endothelium, we have performed KLF2 overexpression

A
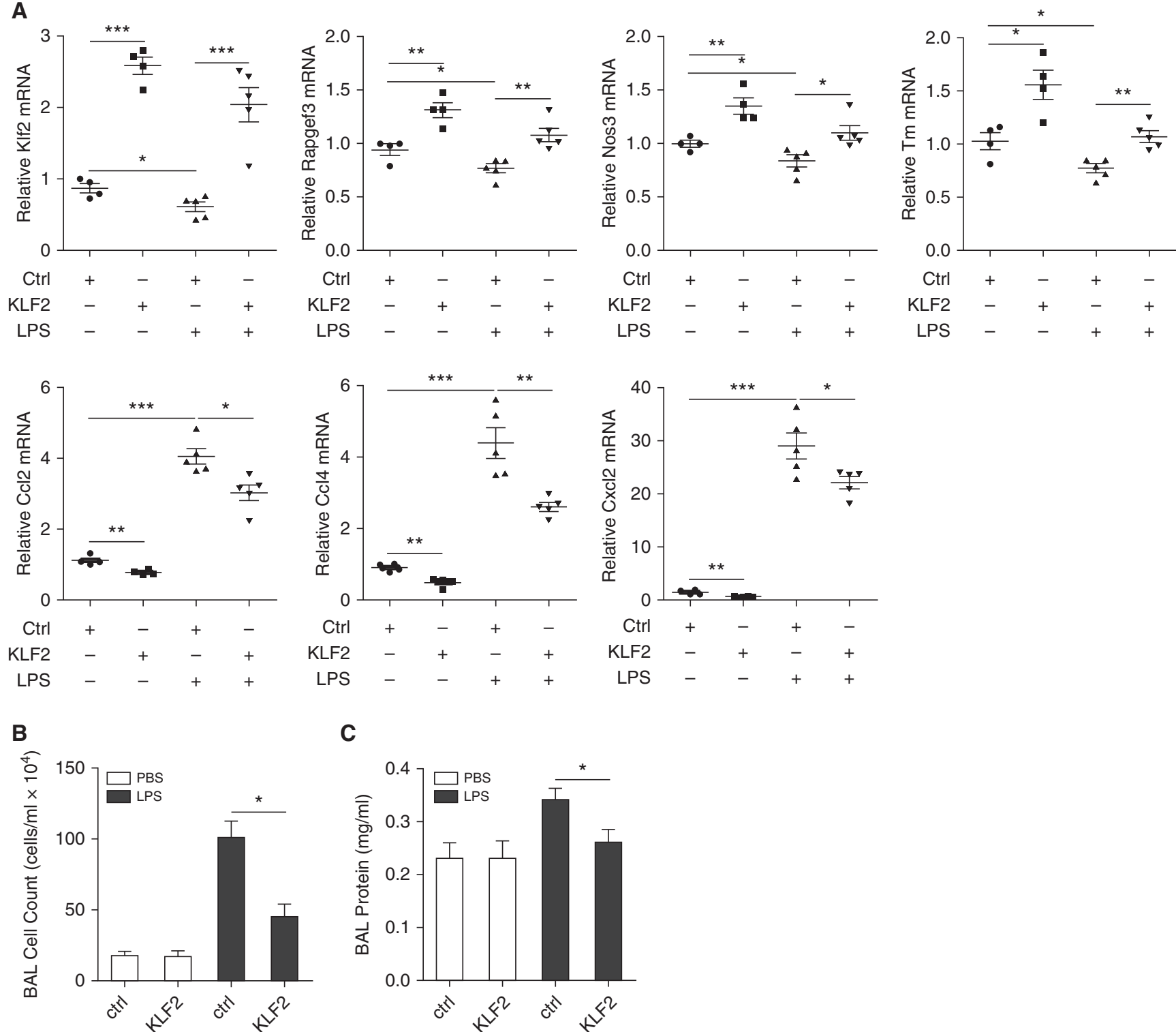

Figure 7. Inflammatory gene expression and parameters of lung injury were mitigated by Krüppel-like factor 2 (KLF2) transient overexpression in vivo. (A) mRNA expression for Klf2, Rapgef3, Nos3, Tm, Ccl2, Ccl4, and Cxcl2 in mice transfected with KLF2-overexpressing plasmid or control plasmid with or without LPS administration. Mice were transfected with KLF2-overexpressing plasmid or control plasmid via tail vein injection before intratracheal administration with $0.7 \mathrm{mg} / \mathrm{kg}$ LPS for 24 hours and killed to collect lung tissues for RNA isolation followed by quantitative real-time polymerase chain reaction. KLF2 overexpression ameliorates KIf2, Rapgef3, and Nos3 reduction by LPS, and reduces up-regulation of CCl2, Cc/4, and CxCl2 by LPS. $n=4-5$. All data are represented as fold change. Circles represent control plasmid/without LPS; squares represent KLF2-overexpressing plasmid/without LPS; triangles pointing up represent control plasmid/LPS; and triangles pointing down represent KLF2-overexpressing plasmid/LPS. Error bars represent \pm SEM. Measurement of bronchoalveolar lavage (BAL) cell count $(B)$ and BAL protein concentration $(C)$ in mice transfected with KLF2-overexpressing plasmid or control plasmid with or without LPS administration. KLF2 overexpression reduces lung injury induced by LPS as measured by protein leak and cell counts. All data are represented as mean $\pm \mathrm{SEM}$. ${ }^{\star} P<0.05,{ }^{\star \star} P<0.01$, ${ }^{\star \star \star} \mathrm{P}<0.001$, Student's $t$ test. $\mathrm{C} C \mathrm{2}$ = C-C motif chemokine ligand 2; CCl4 = C-C motif chemokine ligand 4; CxCl2 = C-X-C motif chemokine ligand 2; ctrl = control; NOS3 = nitric oxide synthase; PBS = phosphate-buffered saline; RAPGEF3 = Rap guanine nucleotide exchange factor 3; TM = thrombomodulin . 
experiments to establish the direct regulation of these ARDS genes by KLF2 in HMVEC. KLF2 induction resulted in significant reduction of inflammatory genes IL6, IL8, and TNF, vasoconstricting ACE, and antifibrinolytic SERPINE1 (Figure 8B). Moreover, the antioxidant reductase NQO1 and NF- $\kappa \mathrm{B}$ inhibitor NFKBIA were significantly increased in HMVEC by KLF2 overexpression (Figure 8B).

Expression of these ARDS GWAS genes was further determined in vivo in mouse lungs as a function of KLF2 expression. Consistent with the in vitro data in HMVEC, Ace, Il6, Il8, Serpine1, and $\operatorname{Tnf}$ were reduced, whereas $\mathrm{Nqo1}$ and Nfkbia were increased in mouse lung as the result of KLF2 overexpression (Figure 8C). The regulation of these ARDS GWAS genes by KLF2 in vivo was also detected in LPS-treated mouse lungs (Figure 8D).

\section{Discussion}

Although KLF2 is abundantly expressed and was first cloned in lungs (20), and is perhaps the critical transcription factor that determines endothelial quiescence (13-15, 17, 43-45), whether KLF2 contributes to pulmonary vascular pathology remains poorly investigated. Herein, using rodent models of ALI, we demonstrate that endogenous KLF2 is significantly reduced in inflamed lungs subjected to influenza A virus, LPS, or high tidal volume ventilation. These in vivo results are in agreement with reduced KLF2 in vitro in HMVEC stimulated by TNF- $\alpha$, LPS, or increased circumferential stretch. Our investigations further highlight an as yet unrecognized regulatory role of KLF2 in small GTPase signaling, particularly in Racl activation and microvascular barrier protection. KLF2 transcriptionally regulates

RAPGEF3 (EPAC1) through its multiple CACCC sites in the promoter; RAPGEF3 mechanistically contributes to Rac1 activation and enhances barrier functions in KLF2-expressing cells. The contributing role of KLF2 in ALI is further supported by KLF2 regulation of a cohort of ARDS genes established by GWAS. Thus, not only is downregulation of KLF2 associated with vascular dysfunction in ALI, but also mechanistically plays a role in the reduced activity of Rac1. Moreover, KLF2 overexpression restores the expression of RAPGEF3 and a cohort of ARDS-associated GWAS genes and ameliorates LPS-induced lung injury in vivo.

The integration of genetic information and network modeling has been used to explore key biologic processes that contribute to clinical traits of common complex human diseases (46). Consistent with a previous study (26), our pathway analyses demonstrate that multiple GWAS-identified ARDS genes form a highly interconnected network and moreover, KLF2 can serve a hub gene to regulate many ARDS-associated genes. In addition to compromised vascular integrity, increased inflammation and amplified coagulation are hallmarks of ARDS pathogenesis. Our in vitro and in vivo results demonstrate that endogenous KLF2 contributes to the quiescent and anticoagulant phenotype of pulmonary microvascular endothelium by transcriptionally activating vascular protective genes NOS3 and TM, increasing antioxidant reductase NQO1 and NF- $\mathrm{KB}$ inhibitor NFKBIA, inactivating cytokines (IL-6, IL-8, TNF- $\alpha$ ), and decreasing adhesion molecule expression (see Figure E7), and suppressing vasoconstrictive ACE and antifibrinolytic SERPINE1. RAPGEF3/ EPAC1 has recently emerged as a critical effector of endothelial homeostasis and cardiac remodeling; however, the molecular mechanisms of EPAC1 regulation remain poorly defined (47). Our results demonstrate that KLF2 is a novel transcriptional regulator that maintains RAPGEF3 expression in endothelium.

In addition to barrier protection $(7,9)$, Racl GTPase has been linked to many other signal transduction pathways that govern cellular proliferation, migration, growth, differentiation, and apoptosis (5). Racl activity is dynamically regulated by numerous stimuli, such as hormones, cytokines, growth factors, and oxidative stress. Our data suggest transcription factors (e.g., KLF2) can actively control the on-off switch of Rac1 cycling between GTP-bound and GDPbound forms by regulating upstream activators of Rac1, such as RAPGEF3.

RAPGEF3 regulation by KLF2 is supported by RAPGEF3 modulation as the result of KLF2 manipulation and moreover, by the presence of five
KLF2 binding sites (CACCC) in the RAPGEF3 promoter. In contrast, expression of other Rac1 upstream activators VAV2 and TIAM1 is not regulated by KLF2, consistent with low and absent CACCC sites in the promoter regions (one CACCC in human VAV2 and no CACCC in human TIAM1 promoter). RAPGEF5 and RAPGEF6, other members of RAS subfamily of GTPases, are not regulated by KLF2 in HMVEC (see Figure E8), in agreement with the lack of multiple CACCC sites in their promoter regions. Moreover, our results demonstrate that KLF2 does not significantly regulate mRNA expression of junctional proteins claudin 5 (CLD5), tight junction protein 1 (ZO-1), afadin (AF6), claudin-12 (CLD12), F11 receptor (JAM1), and occludin (OCLN) that are implicated in barrier function (see Figure E9).

One unique feature of KLF2 is its sensitivity to physical stimuli. Endothelial KLF2 expression is greatly influenced by hemodynamic forces, particularly the shear stress generated by arterial blood flow $(13,17$, $44,48)$. Lung microvasculature is exposed to considerable shear stress because of the small vessel radius (39). Vascular endothelium is decorated by various membrane-bound macromolecules forming the glycocalyx that plays a major role in sensing blood flow (41). Alterations in microvascular circulation (49) and more importantly, the loss of glycocalyx as the result of TNF- $\alpha$ have been reported during lung injury (40). Our data suggest that continuous microvascular flow is a critical regulator of physiologic levels of endogenous endothelial KLF2 and its downstream targets. Moreover, TNF- $\alpha$ pretreatment significantly reduced the flow-sensitivity of KLF2 and the mechanoregulation of its downstream targets to microvascular shear stress in HMVEC. It is plausible that KLF2 reduction in diseased lungs is attributable to the disruption of microvascular blood flow and/or loss of endothelial glycocalyx and hence mechanosensation during ALI. It is important for future studies to determine KLF2 expression in lung tissue from patients with ARDS and precisely measure the pulmonary microvascular flow velocity in experimental lung injury models and moreover, in patients with ARDS.

The studies here further establish the regulation of KLF2 by cyclic stretch; 
A

$\overbrace{\text { Transcriptional Regulato }}$

Enzyme

Peptidase

Y

Cytokine/Growth Factor

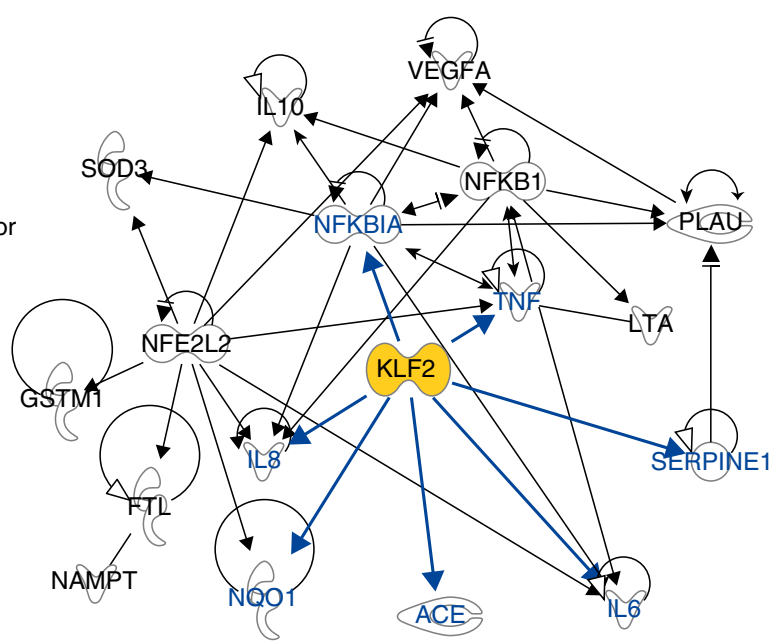

C
A acts on B

A

(A) translocate to $\longrightarrow$ (B)

A binding only (B)

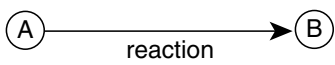

B

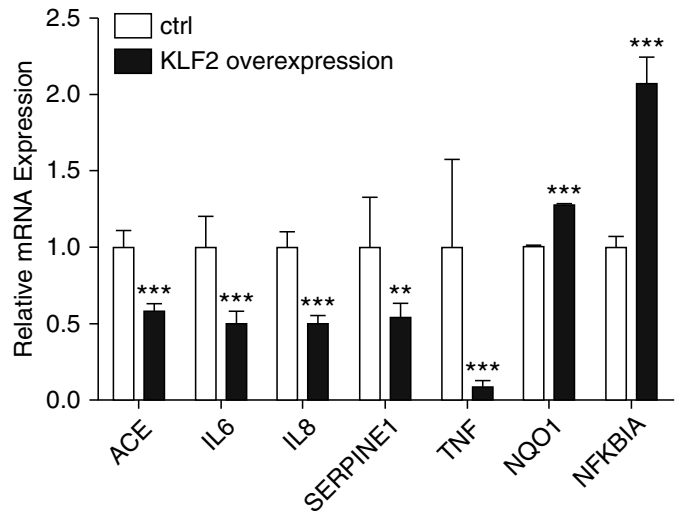

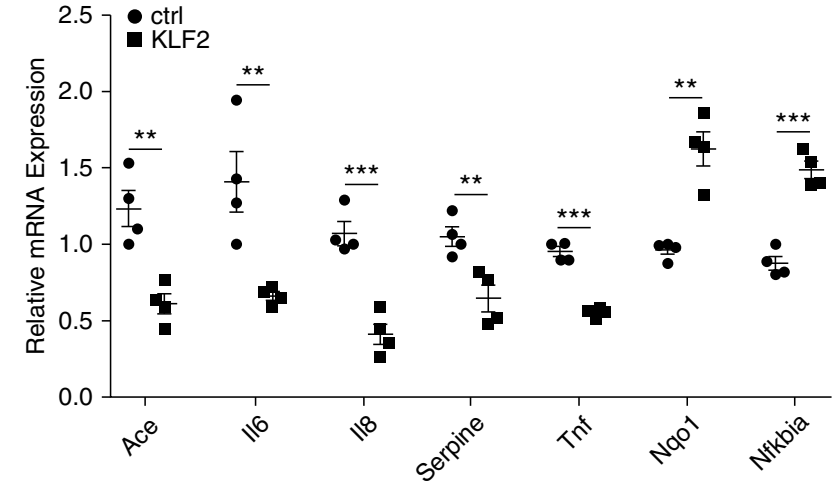

D

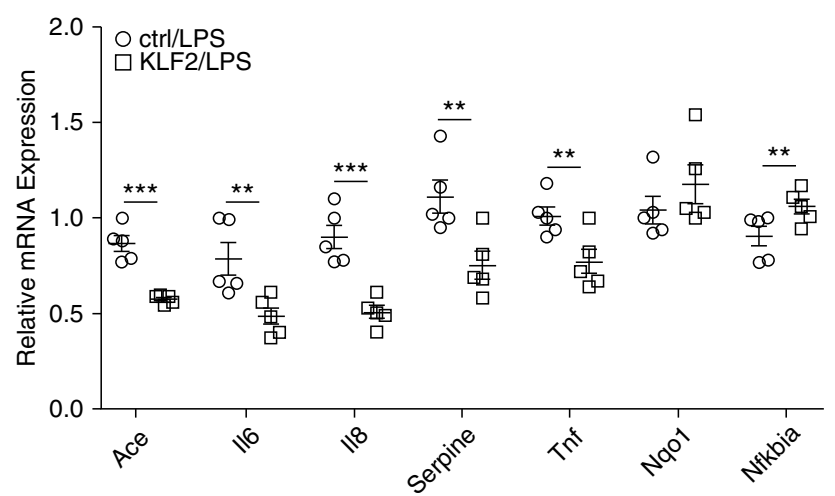

Figure 8. Krüppel-like factor 2 (KLF2) regulates genome-wide association studies-identified acute respiratory distress syndrome genes in vitro and in vivo. (A) Ingenuity Pathway Analysis shows KLF2 plays a central role forming a highly interconnected network with genome-wide association studies-implicated acute lung injury/acute respiratory distress syndrome genes. $(B)$ In human pulmonary microvascular cells overexpressing KLF2 via transfection with KLF2 transcripts (T7-KLF2), mRNA expression for ACE, IL6, IL8, SERPINE1, and TNF $\alpha$ are significantly decreased, whereas NQO1 and NFKBIA mRNA expression are up-regulated compared with T7-ctrl-transfected cells. $\mathrm{n}=6-8$. All data are represented as mean \pm SEM. mRNA expression for Ace, I/6, I/8, Serpine1, Tnf, Nq01, and Nfkbia in mice transfected with KLF2-overexpressing plasmid or control plasmid without (C) or with LPS administration (D) demonstrated significant regulation by KLF2. $\mathrm{n}=4-5$. All data are represented as fold change. Error bars represent $\pm \mathrm{SEM}$. ${ }^{\star \star} P<0.01,{ }^{\star \star \star} P<0.001$, Student's $t$ test. ACE = angiotensin I converting enzyme; ctrl = control; FTL = ferritin light chain; GSTM1 = glutathione S-transferase mu 1; LTA = lymphotoxin- $\alpha$; NAMPT = nicotinamide phosphoribosyltransferase; NFE2L2 = nuclear factor, erythroid 2 like 2; NFKB1 = nuclear factor $\kappa$ B subunit 1; NFKBIA = NFKB inhibitor- $\alpha$; NQO1 = NAD(P)H quinone dehydrogenase 1; PLAU = plasminogen activator, urokinase; SERPINE1 = serpin family E member 1 ; SOD3 = superoxide dismutase $3 ; \mathrm{TNF}=$ tumor necrosis factor; VEGFA = vascular endothelial growth factor $\mathrm{A}$. 
the implication is particularly relevant to lung vascular pathophysiology because pulmonary microvasculature is consistently exposed to physiologic cyclic stretch caused by continuous respiratory cycles and pathologic overdistention related to high-tidal ventilation (29).

In addition to compromised vascular integrity, dysfunctional pulmonary endothelium contributes significantly to the cytokine storm that drives the uncontrolled inflammatory response during ARDS $(3,4)$, and that KLF2 regulates many ARDS GWAS genes $(25,26)$. Our results demonstrate in HMVEC, KLF2 promotes antiinflammatory genes, and suppresses proinflammatory genes (IL6, IL8, TNF, and NFKBIA). In addition, KLF2 suppresses ACE in HMVEC, consistent with a study showing ACE knockout mice are protected from severe ALI (50). ARDS is associated with uncontrolled activation of coagulation pathways and increased oxidants (2), in agreement with KLF2 suppression of SERPINE1 that inhibits fibrinolysis, and KLF2 up-regulation of antioxidant NQO1. Furthermore, Klf2 hemizygous $\left(K l f 2^{+/-}\right)$mice were reported to exhibit worsened LPS-induced sepsis symptoms (51). Our results show that pretreatment of KLF2 overexpression significantly ameliorated LPS-induced lung injury. It is important for future studies to determine the timing for endothelium-specific restoration of KLF2 in inflamed lungs that could promote vascular health to alleviate ARDS, yet maintain appropriate vascular inflammation to fight pathogens. Recent efforts have shown that therapeutic nucleotides can be delivered to inflamed endothelium by vascular cell adhesion protein-1 targeted nanoparticles (52), which could be used for future investigations in developing therapeutics to restore pulmonary endothelial KLF2 in treating ARDS.

Author disclosures are available with the text of this article at www.atsjournals.org.

\section{References}

1. Ware LB, Matthay MA. The acute respiratory distress syndrome. N Engl $J$ Med 2000;342:1334-1349.

2. Matthay MA, Ware LB, Zimmerman GA. The acute respiratory distress syndrome. J Clin Invest 2012;122:2731-2740.

3. Teijaro JR, Walsh KB, Cahalan S, Fremgen DM, Roberts E, Scott F, Martinborough E, Peach R, Oldstone MB, Rosen H. Endothelial cells are central orchestrators of cytokine amplification during influenza virus infection. Cell 2011;146:980-991.

4. London NR, Zhu W, Bozza FA, Smith MC, Greif DM, Sorensen LK, Chen L, Kaminoh Y, Chan AC, Passi SF, et al. Targeting Robo4-dependent Slit signaling to survive the cytokine storm in sepsis and influenza. Sci Transl Med 2010;2:23ra19.

5. Tzima E. Role of small GTPases in endothelial cytoskeletal dynamics and the shear stress response. Circ Res 2006;98:176-185.

6. Dudek SM, Garcia JG. Cytoskeletal regulation of pulmonary vascular permeability. J Appl Physiol (1985) 2001;91:1487-1500.

7. Jacobson JR, Dudek SM, Singleton PA, Kolosova IA, Verin AD, Garcia JG. Endothelial cell barrier enhancement by ATP is mediated by the small GTPase Rac and cortactin. Am J Physiol Lung Cell Mol Physiol 2006; 291:L289-L295.

8. Su G, Atakilit A, Li JT, Wu N, Bhattacharya M, Zhu J, Shieh JE, $\mathrm{Li} E$, Chen R, Sun S, et al. Absence of integrin $\alpha v \beta 3$ enhances vascular leak in mice by inhibiting endothelial cortical actin formation. Am J Respir Crit Care Med 2012;185:58-66.

9. Vandenbroucke E, Mehta D, Minshall R, Malik AB. Regulation of endothelial junctional permeability. Ann N Y Acad Sci 2008;1123: 134-145.

10. Singleton PA, Dudek SM, Chiang ET, Garcia JG. Regulation of sphingosine 1-phosphate-induced endothelial cytoskeletal rearrangement and barrier enhancement by S1P1 receptor, PI3 kinase, Tiam1/Rac1, and alpha-actinin. FASEB J 2005;19: 1646-1656.

11. Tzima E, Del Pozo MA, Kiosses WB, Mohamed SA, Li S, Chien S, Schwartz MA. Activation of Rac1 by shear stress in endothelial cells mediates both cytoskeletal reorganization and effects on gene expression. EMBO J 2002;21:6791-6800.

12. Shikata Y, Rios A, Kawkitinarong K, DePaola N, Garcia JG, Birukov KG. Differential effects of shear stress and cyclic stretch on focal adhesion remodeling, site-specific FAK phosphorylation, and small GTPases in human lung endothelial cells. Exp Cell Res 2005;304: 40-49.

13. Parmar KM, Larman HB, Dai G, Zhang Y, Wang ET, Moorthy SN, Kratz JR, Lin Z, Jain MK, Gimbrone MA Jr, et al. Integration of flowdependent endothelial phenotypes by Kruppel-like factor 2. J Clin Invest 2006;116:49-58.
14. Dekker RJ, Boon RA, Rondaij MG, Kragt A, Volger OL, Elderkamp YW, Meijers JC, Voorberg J, Pannekoek H, Horrevoets AJ. KLF2 provokes a gene expression pattern that establishes functional quiescent differentiation of the endothelium. Blood 2006;107:4354-4363.

15. Lin Z, Kumar A, SenBanerjee S, Staniszewski K, Parmar K, Vaughan DE, Gimbrone MA Jr, Balasubramanian V, García-Cardeña G, Jain MK. Kruppel-like factor 2 (KLF2) regulates endothelial thrombotic function. Circ Res 2005;96:e48-e57.

16. Atkins GB, Jain MK. Role of Krüppel-like transcription factors in endothelial biology. Circ Res 2007;100:1686-1695.

17. SenBanerjee S, Lin Z, Atkins GB, Greif DM, Rao RM, Kumar A, Feinberg MW, Chen Z, Simon DI, Luscinskas FW, et al. KLF2 Is a novel transcriptional regulator of endothelial proinflammatory activation. $J$ Exp Med 2004;199:1305-1315.

18. Lin Z, Natesan V, Shi H, Dong F, Kawanami D, Mahabeleshwar GH, Atkins GB, Nayak L, Cui Y, Finigan JH, et al. Kruppel-like factor 2 regulates endothelial barrier function. Arterioscler Thromb Vasc Biol 2010;30:1952-1959.

19. Shi H, Sheng B, Zhang F, Wu C, Zhang R, Zhu J, Xu K, Kuang Y, Jameson SC, Lin Z, et al. Kruppel-like factor 2 protects against ischemic stroke by regulating endothelial blood brain barrier function. Am J Physiol Heart Circ Physiol 2013;304:H796-H805.

20. Anderson KP, Kern CB, Crable SC, Lingrel JB. Isolation of a gene encoding a functional zinc finger protein homologous to erythroid Krüppel-like factor: identification of a new multigene family. Mol Cell Biol 1995;15:5957-5965.

21. Kuo CT, Veselits ML, Barton KP, Lu MM, Clendenin C, Leiden JM. The LKLF transcription factor is required for normal tunica media formation and blood vessel stabilization during murine embryogenesis. Genes Dev 1997;11:2996-3006.

22. Wani MA, Means RT Jr, Lingrel JB. Loss of LKLF function results in embryonic lethality in mice. Transgenic Res 1998;7:229-238.

23. Chiplunkar AR, Curtis BC, Eades GL, Kane MS, Fox SJ, Haar JL, Lloyd JA. The Krüppel-like factor 2 and Krüppel-like factor 4 genes interact to maintain endothelial integrity in mouse embryonic vasculogenesis. BMC Dev Biol 2013;13:40.

24. Wani MA, Wert SE, Lingrel JB. Lung Kruppel-like factor, a zinc finger transcription factor, is essential for normal lung development. $J$ Biol Chem 1999;274:21180-21185.

25. Reddy AJ, Kleeberger SR. Genetic polymorphisms associated with acute lung injury. Pharmacogenomics 2009;10:1527-1539.

26. Gao L, Barnes KC. Recent advances in genetic predisposition to clinical acute lung injury. Am J Physiol Lung Cell Mol Physiol 2009; 296:L713-L725.

27. Wu DD, Huang RT, Jain M, Birukova AA, Lloyd J, Mutlu GM, Birukov KG, Fang Y. Klf2 enhances barrier protection by directly regulating Rapgef3, a Gef which activates Rac1 [abstract]. Am J Respir Crit Care Med 2016;193:A5754. 
28. Radigan KA, Morales-Nebreda L, Soberanes S, Nicholson T, Nigdelioglu R, Cho T, Chi M, Hamanaka RB, Misharin AV, Perlman H, et al. Impaired clearance of influenza A virus in obese, leptin receptor deficient mice is independent of leptin signaling in the lung epithelium and macrophages. PLoS One 2014;9:e108138.

29. Slutsky AS, Ranieri VM. Ventilator-induced lung injury. N Engl J Med 2013;369:2126-2136.

30. Birukov KG, Jacobson JR, Flores AA, Ye SQ, Birukova AA, Verin AD, Garcia JG. Magnitude-dependent regulation of pulmonary endothelial cell barrier function by cyclic stretch. Am J Physiol Lung Cell Mol Physiol 2003;285:L785-L797.

31. Perlman CE, Bhattacharya J. Alveolar expansion imaged by optical sectioning microscopy. J Appl Physiol (1985) 2007;103:1037-1044.

32. Dubrovskyi O, Birukova AA, Birukov KG. Measurement of local permeability at subcellular level in cell models of agonist- and ventilator-induced lung injury. Lab Invest 2013;93:254-263.

33. Weed SA, Du Y, Parsons JT. Translocation of cortactin to the cell periphery is mediated by the small GTPase Rac1. J Cell Sci 1998; 111:2433-2443.

34. Abe K, Rossman KL, Liu B, Ritola KD, Chiang D, Campbell SL, Burridge K, Der CJ. Vav2 is an activator of Cdc42, Rac1, and RhoA. J Biol Chem 2000;275:10141-10149.

35. de Rooij J, Zwartkruis FJ, Verheijen MH, Cool RH, Nijman SM, Wittinghofer A, Bos JL. Epac is a Rap1 guanine-nucleotideexchange factor directly activated by cyclic AMP. Nature 1998;396: 474-477.

36. Bos JL. Epac: a new cAMP target and new avenues in cAMP research. Nat Rev Mol Cell Biol 2003;4:733-738.

37. Birukova AA, Zagranichnaya T, Alekseeva E, Bokoch GM, Birukov KG. Epac/Rap and PKA are novel mechanisms of ANP-induced Racmediated pulmonary endothelial barrier protection. J Cell Physiol 2008;215:715-724.

38. Maillet M, Robert SJ, Cacquevel M, Gastineau M, Vivien D, Bertoglio J, Zugaza JL, Fischmeister R, Lezoualc'h F. Crosstalk between Rap1 and Rac regulates secretion of sAPPalpha. Nat Cell Biol 2003;5:633-639.

39. Hudlicka O, Brown MD, May S, Zakrzewicz A, Pries AR. Changes in capillary shear stress in skeletal muscles exposed to longterm activity: role of nitric oxide. Microcirculation 2006;13:249-259.

40. Schmidt EP, Yang Y, Janssen WJ, Gandjeva A, Perez MJ, Barthel L, Zemans RL, Bowman JC, Koyanagi DE, Yunt ZX, et al. The pulmonary endothelial glycocalyx regulates neutrophil adhesion and lung injury during experimental sepsis. Nat Med 2012;18:1217-1223.
41. Thi MM, Tarbell JM, Weinbaum S, Spray DC. The role of the glycocalyx in reorganization of the actin cytoskeleton under fluid shear stress: a "bumper-car" model. Proc Natl Acad Sci USA 2004;101: 16483-16488.

42. Calvano SE, Xiao W, Richards DR, Felciano RM, Baker HV, Cho RJ, Chen RO, Brownstein BH, Cobb JP, Tschoeke SK, et al.; Inflamm and Host Response to Injury Large Scale Collab. Res. Program. A network-based analysis of systemic inflammation in humans. Nature 2005;437:1032-1037.

43. Wu W, Xiao H, Laguna-Fernandez A, Villarreal G Jr, Wang KC, Geary GG, Zhang Y, Wang WC, Huang HD, Zhou J, et al. Flow-dependent regulation of Kruppel-like factor 2 is mediated by microRNA-92a. Circulation 2011;124:633-641.

44. Wu C, Huang RT, Kuo CH, Kumar S, Kim CW, Lin YC, Chen YJ, Birukova A, Birukov KG, Dulin NO, et al. Mechanosensitive PPAP2B regulates endothelial responses to atherorelevant hemodynamic forces. Circ Res 2015;117:e41-e53.

45. Fang Y, Davies PF. Site-specific microRNA-92a regulation of Kruppellike factors 4 and 2 in atherosusceptible endothelium. Arterioscler Thromb Vasc Biol 2012;32:979-987.

46. Civelek M, Lusis AJ. Systems genetics approaches to understand complex traits. Nat Rev Genet 2014;15:34-48.

47. Lezoualc'h F, Fazal L, Laudette M, Conte C. Cyclic AMP sensor EPAC proteins and their role in cardiovascular function and disease. Circ Res 2016;118:881-897.

48. Dekker RJ, van Soest S, Fontijn RD, Salamanca S, de Groot PG, VanBavel E, Pannekoek H, Horrevoets AJ. Prolonged fluid shear stress induces a distinct set of endothelial cell genes, most specifically lung Krüppel-like factor (KLF2). Blood 2002;100:1689-1698.

49. De Backer D, Creteur J, Preiser JC, Dubois MJ, Vincent JL. Microvascular blood flow is altered in patients with sepsis. Am J Respir Crit Care Med 2002;166:98-104.

50. Imai Y, Kuba K, Rao S, Huan Y, Guo F, Guan B, Yang P, Sarao R, Wada T, Leong-Poi $\mathrm{H}$, et al. Angiotensin-converting enzyme 2 protects from severe acute lung failure. Nature 2005;436:112-116.

51. Nayak L, Goduni L, Takami Y, Sharma N, Kapil P, Jain MK, Mahabeleshwar GH. Kruppel-like factor 2 is a transcriptional regulator of chronic and acute inflammation. Am J Pathol 2013;182:1696-1704.

52. Kuo CH, Leon L, Chung EJ, Huang RT, Sontag TJ, Reardon CA, Getz GS, Tirrell M, Fang Y. Inhibition of atherosclerosis-promoting microRNAs via targeted polyelectrolyte complex micelles. $J$ Mater Chem B Mater Biol Med 2014;2:8142-8153. 